\title{
Factors influencing caregivers' burden among family caregivers and institutionalization of in-home elderly people cared for by family caregivers
}

\author{
Shigeki Kurasawa $\cdot$ Kouichi Yoshimasu $\cdot$ Masakazu Washio $\cdot$ Jin Fukumoto \\ Shigeki Takemura $\cdot$ Katsushi Yokoi $\cdot$ Yumiko Arai $\cdot$ Kazuhisa Miyashita
}

Received: 14 September 2011/ Accepted: 27 February 2012/Published online: 28 March 2012

(c) The Japanese Society for Hygiene 2012

\begin{abstract}
Objectives The purpose of this study was to determine the factors related to changes in the burden of caregivers who look after the elderly at home, as well as factors related to the institutionalization of the elderly who require care. The types of care services associated with reducing caregivers' burden and continuing in-home care were also studied.

Methods The study subjects were adults aged $\geq 65$ years who used the services of in-home care management centres located in Osaka Prefecture, Japan, and their caregivers. This 2-year longitudinal study began in October 2007, with
\end{abstract}

S. Kurasawa $(\bowtie)$

Department of Rehabilitation Sciences, Kansai University

of Welfare Sciences, 3-11-1 Asahigaoka,

Kashiwara 582-0026, Japan

e-mail: kurasawa@fuksi-kagk-u.ac.jp

S. Kurasawa - K. Yoshimasu - J. Fukumoto - S. Takemura .

K. Yokoi · K. Miyashita

Department of Hygiene, School of Medicine,

Wakayama Medical University, 811-1 Kimiidera,

Wakayama 641-8509, Japan

M. Washio

Department of Community Health and Clinical Epidemiology,

St. Mary's College, 422 Tsubuku-hon-machi,

Kurume 830-8558, Japan

M. Washio · Y. Arai

Department of Gerontological Policy, National Center

for Geriatrics and Gerontology, 36-3 Gengo, Morioka-cho,

Obu 474-8522, Japan

K. Yokoi

Department of Health and Medical Care, Himeji Dokkyo

University, 7-2-1 Kamiono, Himeji 670-8524, Japan a total of three surveys undertaken once a year. The survey methods included self-administered questionnaires and the review of clinical records.

Results Dementia and its accompanying behavioural disturbances were found to be significantly related to the increased burden of caregivers and the institutionalization of those requiring care. A significantly higher proportion of caregivers with an increasing burden or those who maintained a high level of burden used day care services compared to those in the other groups.

Conclusion Preventive intervention against dementia and its accompanying behavioural disturbances should be considered in the day care service to reduce caregivers' burden and to decrease institutionalization.

Keywords Caregiver - Caregiving · Elderly · Caregiver burden · Institutionalization

\section{Introduction}

International surveys conducted over the last few decades have confirmed the fact that caregivers who provide in-home care experience a great deal of stress [1-3]. However, effective methods for reducing such stress have not necessarily been established [4]. It has been confirmed that caregivers' stress and their burden affect not only their own health but also result in the institutionalization of those they care for [5]. Many Japanese elderly who require care wish to be cared for at home, which suggests that there is an increasing social need for in-home care [6].

Earlier published studies in Japan have confirmed that there is a positive association between caregivers' burden and depression [7-10] and that caregivers' burden or 
depressive symptoms increase in those who care for the frail elderly with behavioural disturbances accompanied by dementia [7, 11, 12]. This is particularly evident among caregivers who have no other family member to help care for the elderly [9], who spend a long time caring for an elderly individual $[10,13]$, who can be away from the elderly for more than a very short time [13]. In addition, depressive symptoms and heavy burdens on caregivers have reportedly been associated with an increased risk of discontinuance of in-home care (i.e., institutionalization of the elderly whom they care for) $[14,15]$.

The social situation in Japan for the elderly and their caregivers has seen momentous changes. The public longterm care insurance system for the elderly (LTCIS) was launched in April 2000 with the aim of promoting greater autonomy of the frail elderly in daily life as well as reducing the burden on their caregivers. This system has three main characteristics. Firstly, participation in the system is compulsory. Since LTCIS is financially maintained by a combination of insurance payments from all people aged 40 years or older and governmental subsidies, any eligible person has the right to take advantage of this system. Secondly, feeble elderly who need services from the LTCIS are catergorized into two groups: 'those requiring support' and 'those requiring care,' depending upon the level of care required. The care for 'those requiring care' is further divided into five levels, with differences in the range of available services offered at each level. Thirdly, the in-home care management centre plays a central role in care management, and the 'care manager' was established as an official profession. Care managers perform a wide range of user-support duties, from planning care services to supporting the use of available services.

These dramatic changes in the circumstances of caregiving may have affected caregivers' burden and institutionalization. Therefore, it is necessary to re-evaluate the status of elderly care in Japan. However, in the intervening years since the LTCIS was established, few studies have been conducted on in-home care management centres involving caregivers' burden and institutionalization. Furthermore, there have been no longitudinal studies considering all types of services offered by LTCIS. Ours is a longitudinal study, involving in-home support to elderly people requiring care. The aim is to determine the factors related to changes in the burden of caregivers who care for the elderly at home, as well as those factors related to the institutionalization of the elderly requiring care. Our purpose also includes investigating what types of care services are associated with reducing caregivers' burden and continuing in-home care.

\section{Materials and methods}

Study subjects

This was a longitudinal study conducted in cooperation with six in-home care management centres in Osaka Prefecture, Japan, from October 2007 to October 2009. Baseline data (T1) were obtained from 1 October 2007 to 31 October 2007, and two surveys were conducted once a year during the next 2 years: T2 (2008) and T3 (2009). At T1 there were a total of 203 pairs of people, consisting of the elderly in need of care and their caregivers, receiving some form of service from any of the six facilities. Of these, 133 pairs $(65.5 \%)$ gave their consent to participate in this study.

\section{Measurements}

Information was obtained from self-administered questionnaires and clinical records. The care manager in charge of each subject distributed the questionnaires after obtaining written consent. Subjects returned their self-administered questionnaires by mail, and additional data were obtained from clinical records. The following five questionnaires were used to evaluate the caregiving circumstances of the elderly requiring care and their caregivers: (1) the Japanese version of the Zarit Burden Interview (J-ZBI) [16, 17]; (2) the Japanese version of the Centre for Epidemiologic Studies Depression Scale (CES-D Scale) [18]; (3) the Japanese version of the Neuropsychiatric Inventory Brief Questionnaire Form (NPI-Q) [19]; (4) the demographic characteristics of the elderly in need of care and their caregivers; (5) the per-day time spent on caregiving and attending the elderly, the amount of time during which caregivers can be away from the elderly and the duration of caregiving. The ZBI, which has 22 questions, is one of the most common scales used to evaluate caregivers' burden. Possible scores range from 0 to 88, with higher scores indicating higher levels of burden [1]. CES-D is a self-administered scale with 20 questions that evaluate the severity of depressive symptoms. The total score ranges from 0 to 60 , with a score of $\geq 16$ indicating clinical depressive status [20]. NPI-Q is a scale for the evaluation of behavioural disturbances accompanied by dementia to be completed by the caregiver [21]. The Japanese version of NPI-Q has ten questions (delusions, hallucinations, agitation, dysphoria, anxiety, euphoria, apathy, disinhibition, irritability and aberrant motor behaviour). It evaluates the severity of each symptom and the caregivers' burden by calculating a total score. Since overall caregivers' burden was evaluated by J-ZBI in the current study, NPI-Q was used to evaluate the severity of each symptom. 
The following three kinds of information were obtained from the clinical records: (1) the level of necessary care, (2) the underlying disease, including dementia and (3) the use of care services. In addition, based on the attending physician's diagnosis, the International Classification of Diseases - 10th Revision was used as a reference to classify the underlying diseases of the elderly requiring care. We subsequently reclassified those diseases into the following five categories: neoplasms, diabetes mellitus, ischemic heart diseases, cerebrovascular diseases and others in accordance with the classification by the Ministry of Health, Labour and Welfare in Japan. We classified dementia separately since previous studies have reported that dementia is strongly related to caregivers' burden and institutionalization [22, 23].

This study was approved by the Research Ethics Committee of Wakayama Medical University.

\section{Statistical analysis}

The following two outcomes were selected: (1) worsening of caregivers' burden or maintenance of a high level of caregivers' burden, and (2) discontinuation of in-home care (institutionalization). The analyses were conducted as follows. We first divided the subject pairs into a 'successful' or 'unsuccessful' group based on changes in each caregiver's burden from $\mathrm{T} 1$ to $\mathrm{T} 2$, and then we investigated factors related to those 'successful' or 'unsuccessful' domains. The classification method of Whitlatch et al. [24] was used to determine 'successful' or 'unsuccessful'. This approach is designed to consider regression to the mean and was used before the LTCIS was launched [14]. Individuals with a high burden would need to show considerable change to be classified in the successful group because of the tendency for scores to regress to the mean. On the other hand, if the low scores were maintained or even slightly increased, they were still classified as the successful group for those with a low burden. More specifically, we divided caregivers into quartiles based on each caregiver's J-ZBI score for T1. Caregivers in the top quartile were classified as 'successful' if their J-ZBI score decreased by $\geq 1.0$ standard deviation (SD) unit (16.62 points). On the other hand, if the score decreased by $\leq 1.0$ SD unit or the score increased, caregivers were classified as 'unsuccessful.' Caregivers assigned to the medium-high quartile in T1 were considered 'successful' if their J-ZBI score decreased by $\geq 0.5$ SD unit ( 8.31 points), and all others were classified as 'unsuccessful.' Since caregivers assigned to the medium-low quartile were those already with a low burden, any amount of decline indicated a 'successful' outcome, while all others fell into the 'unsuccessful' category. Those in the lowest quartile whose scores decreased, remained unchanged or increased by
$<0.5$ SD unit were classified as 'successful,' and all others as 'unsuccessful' (Fig. 1). This process left 87 people who were continuing in-home care at the time of T2. The analysis was restricted to those who had stable living conditions during the period from $\mathrm{T} 1$ to $\mathrm{T} 2$, since changes in mental and somatic functions and the service use of the care receivers are considered to greatly influence the caregivers' burden. Consequently, a total of 11 people whose need for care changed two levels or more and whose utilization of care services changed by $\geq 1.0 \mathrm{SD}$ unit were excluded from the assessment, thus leaving 76 subjects.

The second step was the investigation of institutionalization (i.e. facilities covered by LTCIS). We combined the results of $\mathrm{T} 2$ and $\mathrm{T} 3$ and classified the subjects into various groups according to those results. The groups into which subjects were classified were (1) those who were continuing in-home care (continuing group) and (2) those who were institutionalized (institutionalized group), which were used in this analysis; (3) those whose elderly requiring care died; (4) those whose caregivers changed; (5) those whose elderly were hospitalized due to deterioration of health; (6) those who refused to be reassessed; (7) those who were excluded because their health condition improved; (8) those who transferred their care to another in-home care management centre. We compared the continuing group (1)

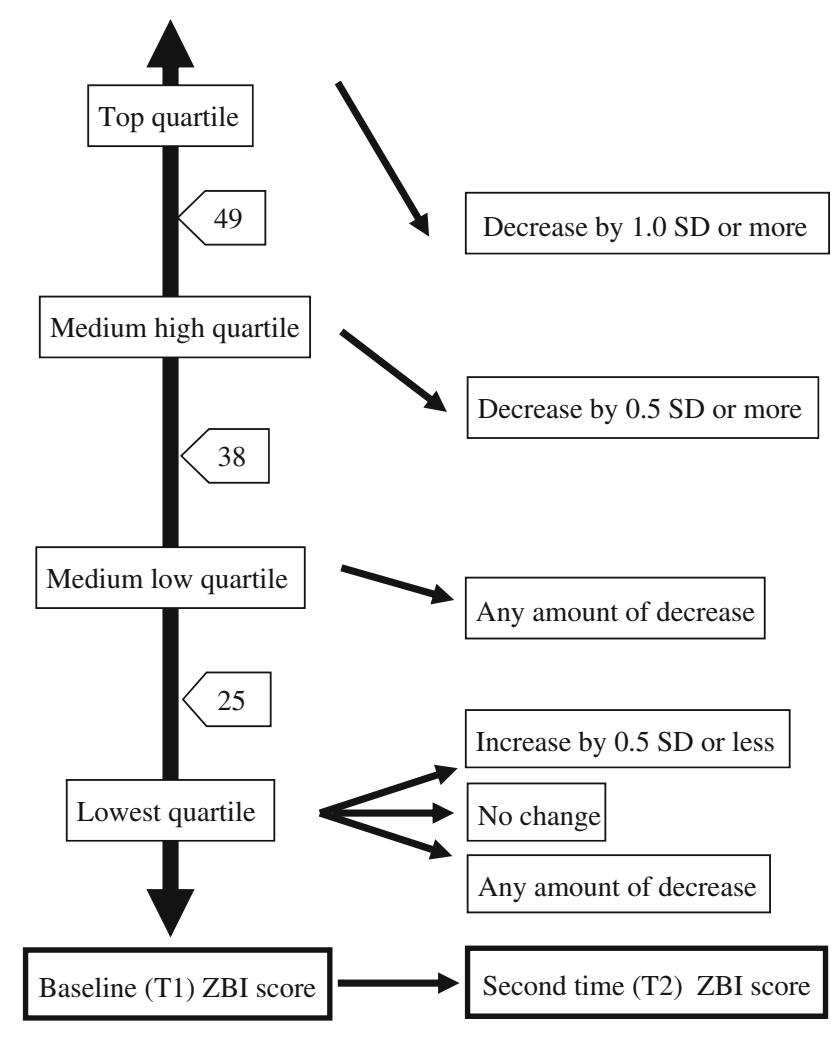

Fig. 1 Definition of successful group. T1 Baseline time-point, T2 second assessment time-point (second year), ZBI Zarit Burden Interview 
with the institutionalized group (2) with respect to the relevant factors. Because we could not contact the other groups during the follow-up period, they were excluded from the analysis. The variables used were data obtained immediately before the results, i.e. T2 for the continuing group and either $\mathrm{T} 1$ or $\mathrm{T} 2$ for the institutionalized group (Fig. 2). Age was additionally adjusted for comparisons between the continuing and institutionalized groups since those requiring care in the institutionalized group were significantly older $(p<0.001)$, and age could be regarded as an important confounding factor between those groups.

The chi-square $\left(\chi^{2}\right)$ test, Mann-Whitney $U$ test, $t$ test and Mantel-Haenszel test were used for each corresponding analytical section. All statistical calculations were conducted by SPSS ver. 16.0. The level of significance was set at $p<0.05$ (two-sided).

\section{Results}

Characteristics of the 133 people who consented to participate in this study at the time of T1 are shown in Table 1. The average age of the elderly requiring care was 81.9 years, of whom $65.4 \%$ were women and $42.1 \%$ had dementia. The average age of caregivers was 63.5 years, of whom $67.7 \%$ were women. The average level of caregivers' burden in JZBI scores was 37.0 points, and $42.9 \%$ of the caregivers suffered from depressive symptoms, which are comparable with the findings of previous studies $[8,10,25,26]$.

Factors related to the successful group

Factors related to changes in caregivers' burden are indicated in Table 2. All of the variables used as potential factors were data obtained from the baseline time-point (T1). Among the 76 people eligible for analysis, 39 caregivers fell in the successful group and 37 in the unsuccessful group. The proportion of dementia was significantly higher and behavioural disturbances were significantly more severe in the unsuccessful group. In contrast, those requiring care in the successful group tended to have

Table 1 Characteristics of subjects $(n=133)$

\begin{tabular}{ll}
\hline Subjects of the study & Data $^{\mathrm{a}}$ \\
\hline Elderly people requiring care & \\
Male & $46(34.6)$ \\
Age & $81.9 \pm 8.5$ \\
Requiring care level: severe $(3+)$ & $62(46.6)$ \\
Behavioral disturbances & $5.2 \pm 5.1$ \\
Underlying diseases & $56(42.1)$ \\
Dementia & $2(1.5)$ \\
Neoplasms & $18(13.5)$ \\
Diabetes mellitus & $34(25.6)$ \\
Ischemic heart diseases & $40(30.1)$ \\
Cerebrovascular diseases & $115(86.5)$ \\
Others & \\
Caregivers & $43(32.3)$ \\
Male & $63.5 \pm 11.7$ \\
Age & \\
CES-D & $15.4 \pm 7.53$ \\
Score & $57(42.9)$ \\
Depressed & $37.0 \pm 16.6$ \\
J-ZBI & $D e p r e s s i s c a, ~$
\end{tabular}

$C E S-D$ Center for Epidemiologic Studies Depression Scale, J-ZBI Japanese version of the Zarit Burden Interview

${ }^{\text {a }}$ Data are presented as the number of subjects $(n)$, with the percentage given in parenthesis, or as the mean \pm standard deviation (SD), as appropriate
Fig. 2 Flow diagram of subject progress from baseline (TI) to third assessment time-point (T3)

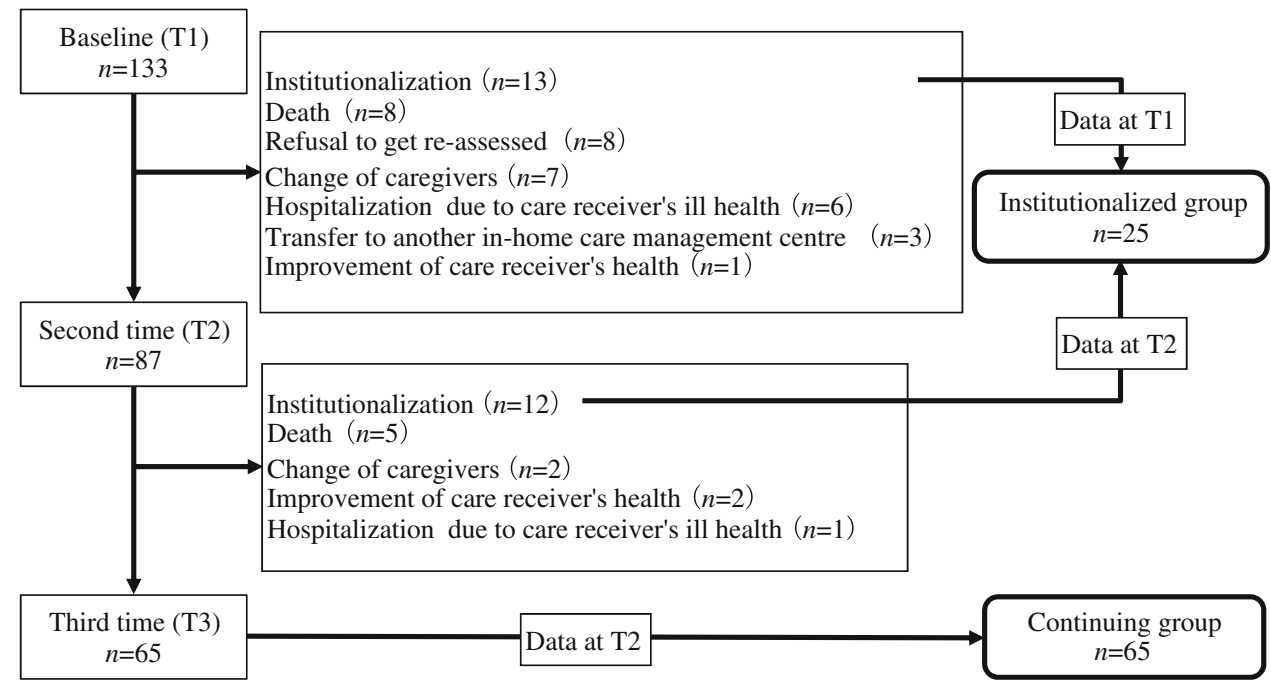


Table 2 Comparisons between the successful group and unsuccessful group in terms of elderly requiring care

\begin{tabular}{|c|c|c|c|}
\hline Variables $^{\mathrm{a}}$ & $\begin{array}{l}\text { Successful } \\
\text { group } \\
(n=39)\end{array}$ & $\begin{array}{l}\text { Unsuccessful } \\
\text { group } \\
(n=37)\end{array}$ & $p$ value \\
\hline Male & $11(28.2)$ & $11(29.7)$ & $0.884^{\mathrm{b}}$ \\
\hline Age & $81.1 \pm 8.3$ & $82.0 \pm 8.4$ & $0.636^{\mathrm{c}}$ \\
\hline $\begin{array}{l}\text { Requiring care level: severe } \\
(3+)\end{array}$ & $18(46.2)$ & $13(35.1)$ & $0.329^{\mathrm{b}}$ \\
\hline No. of family members & $3.1 \pm 1.4$ & $3.0 \pm 1.3$ & $0.956^{\mathrm{c}}$ \\
\hline Behavioral disturbances & $3.7 \pm 4.4$ & $6.0 \pm 5.0$ & $0.036^{\mathrm{c}}$ \\
\hline \multicolumn{4}{|l|}{ Underlying diseases } \\
\hline Dementia & $11(28.2)$ & $19(51.4)$ & $0.039^{\mathrm{b}}$ \\
\hline Diabetes mellitus & $8(20.5)$ & $4(10.8)$ & $0.246^{\mathrm{b}}$ \\
\hline Ischemic heart diseases & $11(28.2)$ & $9(24.3)$ & $0.701^{\mathrm{b}}$ \\
\hline Cerebrovascular diseases & $16(41.0)$ & $8(21.6)$ & $0.069^{\mathrm{b}}$ \\
\hline Others & $31(79.5)$ & $33(89.2)$ & $0.246^{\mathrm{b}}$ \\
\hline
\end{tabular}

${ }^{a}$ Data are presented as the number of subjects $(n)$, with the percentage given in parenthesis, or as the mean $\pm \mathrm{SD}$, as appropriate

b Chi-square test

c Mann-Whitney $U$ test

cerebrovascular disease $(p=0.069)$. The proportions of other physical diseases did not differ between the groups.

In terms of the caregivers (Table 3), those in the unsuccessful group spent a significantly longer time caregiving and attending the elderly. A comparison of utilized care services between the two groups (Table 4) indicated that a significantly higher proportion of those in the unsuccessful group made use of day care service, while day rehabilitation service was less frequently used, not reaching statistical significance $(p=0.080)$. There was no significant difference in the degree of service use $(p=0.659)$.

Factors related to institutionalization

Outcomes regarding subjects from baseline to $\mathrm{T} 3$ are shown in Fig. 2. Of the total 133 participants, 25 were institutionalized, 13 died, nine experienced a change in caregivers, eight refused re-assessment, seven were hospitalized due to deteriorating health of care receiver, and three were excluded from the survey due to improvement of their condition. Also, three subjects transferred to another in-home care management centre and subsequently lost to follow-up.

For our analysis of the factors that affect caregivers' burden in the continuing group $(n=65)$ and the institutionalized group $(n=25)$, we first divided the factors into three domains, namely, characteristics of those requiring care (Table 5), characteristics of caregivers (Table 6), and the status of care service use (Table 7) and assessed the factors between and within domains. Those requiring care in the institutionalized group were significantly older than those in the continuing group (Table 5). Although elderly persons with dementia and the accompanying behavioural disturbances, as well as their use of day care service, degree of service use and the quantity of monthly service units were more apparent in the institutionalized group, once the age of those requiring care was adjusted for, there were no material differences in these factors between the continuing and institutionalized groups (Tables 5, 7). Caregivers in the institutionalized group were significantly more likely to be the daughters-in-law of those requiring care, and to suffer depressive symptoms. On the other hand, caregivers' burden did not differ between the two groups (Table 6). The institutionalized group was more likely to use short-stay services, while a significantly higher proportion of people in the continuing group used home renovation services (Table 7).

\section{Discussion}

Factors related to the successful group

Our longitudinal study showed that the prevalence of dementia among the elderly was higher and that behavioural disturbances were more severe in the unsuccessful group, which is consistent with many other cross-sectional studies that have shown a positive relationship between the burden or depressive symptoms of the caregiver and the behavioural disturbances associated with dementia $[7,11$, 27-31]. In addition, caregivers spent a significantly longer time caregiving and attending the elderly in the unsuccessful group, which is also consistent with previous findings [7, 10-13]. Dementia with behavioral disturbances was shown to be associated with depressive symptoms of caregivers before and after establishment of the LTCIS [12] and, compared to lightly burdened caregivers, heavily burdened caregivers were reported to spend more time caregiving and to have less time to participate in activities without their charges [13]. Caregiving and attending to the elderly is generally influenced by the level of care required and the amount of services available. In our study, however, there were no large differences between the groups in terms of the level of care required and the amount of services provided at baseline. Although our sub-analysis showed that the time spent on caregiving was positively related to the presence of dementia and the accompanying behavioural disturbances, the time spent attending to the elderly was not (data not shown). These findings suggest that the long time spent attending to the elderly in the unsuccessful group may be due to unsuitable care services rather than dementia and its accompanying behavioural problems. 
Table 3 Comparisons between successful group and unsuccessful groups of caregivers

\begin{tabular}{llll}
\hline Variables $^{\mathrm{a}}$ & Successful group $(n=39)$ & Unsuccessful group $(n=37)$ & $p$ value \\
\hline Male & $14(35.9)$ & $13(35.1)$ & $0.945^{\mathrm{b}}$ \\
Age & $62.4 \pm 10.8$ & $62.7 \pm 12.3$ & $0.632^{\mathrm{c}}$ \\
Time spent caregiving (h/day) & $2.4 \pm 1.6$ & $4.0 \pm 4.1$ & $0.045^{\mathrm{c}}$ \\
Time spent attending elderly (h/day) & $3.7 \pm 6.3$ & $5.0 \pm 5.1$ & $3.3 \pm 2.7$ \\
Time when caregivers can leave without the elderly (h/day) & $4.0 \pm 2.6$ & $61.2 \pm 49.5$ \\
Duration of caregiving (months) & $55.4 \pm 48.2$ & $9(24.3)$ & $0.195^{\mathrm{c}}$ \\
Have a job & $13(33.3)$ & $14(37.8)$ & $0.412^{\mathrm{c}}$ \\
Relationship of caregiver to elderly & & $6(16.2)$ & $0.387^{\mathrm{b}}$ \\
$\quad$ Spouse vs. others & $15(38.5)$ & $8(20.5)$ & $0.955^{\mathrm{b}}$ \\
$\quad$ Daughter-in-law vs. others & & $16.0 \pm 8.1$ \\
CES-D & $13.4 \pm 5.7$ & $16(43.2)$ \\
$\quad$ Score & $12(30.8)$ & $0.629^{\mathrm{b}}$ \\
$\quad$ Depressed & & $0.107^{\mathrm{d}}$ \\
\hline
\end{tabular}

$C E S-D$ Center for Epidemiologic Studies Depression Scale, J-ZBI Japanese version of the Zarit Burden Interview

${ }^{a}$ Data are presented as the number of subjects $(n)$, with the percentage given in parenthesis, or as the mean $\pm \mathrm{SD}$, as appropriate

b Chi-square test

c Mann-Whitney $U$ test

${ }^{\mathrm{d}} t$ test

Table 4 Comparisons between successful group and unsuccessful group in use of care services

\begin{tabular}{llll}
\hline Care services $^{\mathrm{a}}$ & Successful group $(n=39)$ & Unsuccessful group $(n=37)$ & $p$ value \\
\hline Home help service (times/month) & $3.8 \pm 6.9$ & $5.4 \pm 8.2$ & $0.304^{\mathrm{c}}$ \\
Home-visit bathing service (times/month) & $0.2 \pm 1.0$ & $0.2 \pm 1.5$ & $0.611^{\mathrm{c}}$ \\
Home-visit nursing (times/month) & $0.6 \pm 2.1$ & $0.2 \pm 0.9$ & $0.411^{\mathrm{c}}$ \\
Home-visit rehabilitation (times/month) & $2.0 \pm 4.1$ & $5.6 \pm 5.6$ & $0.167^{\mathrm{c}}$ \\
Day care service (times/month) & $2.8 \pm 4.3$ & $0.8 \pm 3.0$ & $0.010^{\mathrm{c}}$ \\
Day rehabilitation service (times/month) & $2.5 \pm 4.7$ & $0.9 \pm 3.2$ & $19(51.4)$ \\
Short-stay service (times/month) & $0.6 \pm 2.0$ & $6(16.2)$ & $0.080^{\mathrm{c}}$ \\
Rental of welfare equipment & $22(56.4)$ & $10,634.3 \pm 8,138.9$ & $0.820^{\mathrm{c}}$ \\
Home renovation service & $4(10.3)$ & $44.5 \pm 27.8$ & $0.334^{\mathrm{d}}$ \\
Quantity of service use (times/month) & $1,0279.1 \pm 7,687.0$ & $0.988^{\mathrm{c}}$ \\
Degree of service use & $41.2 \pm 26.4$ & $0.659^{\mathrm{c}}$
\end{tabular}

${ }^{a}$ Data are presented as the number of subjects $(n)$, with the percentage given in parenthesis, or as the mean $\pm \mathrm{SD}$, as appropriate

${ }^{\mathrm{b}}$ Degree of service use: quantity of service use/limits to benefits per month, evaluated as (\%)

c Mann-Whitney $U$ test

${ }^{\mathrm{d}}$ Chi-square test

Notably, in the unsuccessful group, there were few subjects who used day rehabilitation services, while a significantly higher proportion of them used day care services. These two services have many similar features, the most significant one being that they are provided during the daytime (usually for $6 \mathrm{~h}$ ). On the other hand, one critical difference is that day rehabilitation services are provided in hospitals, while day care services are provided in social welfare facilities. Therefore, in a day rehabilitation service, those requiring care can receive both medical and rehabilitation therapies. One interventional research project [32] suggested that providing counselling for caregivers and occupational activities for patients with dementia at the same time resulted in a decrease in the behavioural problems of the patients and the burden to caregivers. Another study [33] also demonstrated that occupational therapy improved behavioural disturbances related to dementia and caregiver competence. Although these reports, including the medical service, might support our findings, the combined effect of 
Table 5 Comparisons between continuing group and institutionalized group of elderly requiring care

\begin{tabular}{|c|c|c|c|c|}
\hline Variables $^{\mathrm{a}}$ & $\begin{array}{l}\text { Continuing group } \\
(n=65)\end{array}$ & $\begin{array}{l}\text { Institutionalized group } \\
(n=25)\end{array}$ & $p$ value & $\begin{array}{l}\text { Adjusted }^{\mathrm{b}} \\
p \text { value }\end{array}$ \\
\hline Male & $22(33.8)$ & $6(24.0)$ & $0.366^{\mathrm{c}}$ & 0.890 \\
\hline Age, mean & $81.1 \pm 7.9$ & $87.6 \pm 6.9$ & $<0.001^{\mathrm{d}}$ & - \\
\hline Requiring care level: severe $(3+)$ & $32(49.2)$ & $17(68.0)$ & $0.109^{\mathrm{c}}$ & 0.353 \\
\hline No. of family members & $3.2 \pm 1.5$ & $3.6 \pm 1.5$ & $0.141^{\mathrm{e}}$ & $0.725^{\mathrm{f}}$ \\
\hline Behavioral disturbances & $4.4 \pm 4.3$ & $8.0 \pm 6.4$ & $0.012^{\mathrm{e}}$ & $0.229^{\mathrm{f}}$ \\
\hline \multicolumn{5}{|l|}{ Underlying diseases } \\
\hline Dementia & $25(38.5)$ & $16(64.0)$ & $0.029^{\mathrm{c}}$ & 0.441 \\
\hline Neoplasms & $1(1.5)$ & $0(0.0)$ & $1.000^{\mathrm{c}}$ & 0.231 \\
\hline Diabetes mellitus & $9(13.8)$ & $6(24.0)$ & $0.343^{\mathrm{c}}$ & 0.527 \\
\hline Ischemic heart diseases & $15(23.1)$ & $7(28.0)$ & $0.626^{\mathrm{c}}$ & 0.964 \\
\hline Cerebrovascular diseases & $20(30.8)$ & $8(32.0)$ & $0.910^{\mathrm{c}}$ & 0.963 \\
\hline Others & $58(89.2)$ & $19(76.0)$ & $0.177^{\mathrm{c}}$ & 0.211 \\
\hline
\end{tabular}

${ }^{a}$ Data are presented as the number of subjects (n), with the percentage given in parenthesis, or as the mean $\pm \mathrm{SD}$, as appropriate

b Mantel-Haenszel test (adjusted for age of the elderly requiring care)

c Chi-square test

${ }^{\mathrm{d}} t$ test

e Mann-Whitney $U$ test

${ }^{\mathrm{f}}$ The cut-off point was set as the median value

Table 6 Comparisons between continuing group and institutionalized group of caregivers

\begin{tabular}{|c|c|c|c|c|}
\hline Variables $^{\mathrm{a}}$ & $\begin{array}{l}\text { Continuing group } \\
(n=65)\end{array}$ & $\begin{array}{l}\text { Institutionalized } \\
\text { group }(n=25)\end{array}$ & $p$ value & $\begin{array}{l}\text { Adjusted } \\
p \text { value }\end{array}$ \\
\hline Male & $20(30.8)$ & $8(32.0)$ & $0.910^{\mathrm{c}}$ & 0.637 \\
\hline Age & $63.9 \pm 10.0$ & $61.2 \pm 13.8$ & $0.225^{\mathrm{d}}$ & $0.941^{\mathrm{f}}$ \\
\hline Time spent caregiving (h/day) & $3.2 \pm 2.4$ & $3.9 \pm 3.5$ & $0.528^{\mathrm{d}}$ & $0.973^{\mathrm{f}}$ \\
\hline Time spent attending elderly (h/day) & $5.3 \pm 6.0$ & $7.2 \pm 7.8$ & $0.428^{\mathrm{d}}$ & $0.893^{\mathrm{d}}$ \\
\hline Time when caregivers can leave without the elderly (h/day) & $3.6 \pm 3.6$ & $2.8 \pm 2.6$ & $0.335^{\mathrm{d}}$ & $0.985^{\mathrm{f}}$ \\
\hline Duration of caregiving (months) & $66.4 \pm 48.1$ & $54.5 \pm 23.1$ & $0.583^{\mathrm{d}}$ & $0.399^{\mathrm{f}}$ \\
\hline Have a job & $19(29.2)$ & $8(32.0)$ & $0.797^{\mathrm{c}}$ & 0.924 \\
\hline \multicolumn{5}{|l|}{ Relationship of caregiver to elderly } \\
\hline Spouse vs. others & $27(41.5)$ & $7(28.0)$ & $0.235^{\mathrm{c}}$ & 0.338 \\
\hline Daughter-in-law vs. others & $10(15.4)$ & $13(52.0)$ & $0.001^{\mathrm{c}}$ & 0.016 \\
\hline \multicolumn{5}{|l|}{ CES-D } \\
\hline Score & $14.6 \pm 9.2$ & $17.8 \pm 9.1$ & $0.087^{\mathrm{d}}$ & $0.051^{\mathrm{f}}$ \\
\hline Depressed & $21(32.3)$ & $15(60.0)$ & $0.016^{\mathrm{c}}$ & 0.037 \\
\hline J-ZBI & $35.1 \pm 19.1$ & $39.2 \pm 17.4$ & $0.356^{\mathrm{e}}$ & $0.360^{\mathrm{f}}$ \\
\hline
\end{tabular}

CES-D Center for Epidemiologic Studies Depression Scale, J-ZBI Japanese version of the Zarit Burden Interview

${ }^{a}$ Data are presented as the number of subjects $(n)$, with the percentage given in parenthesis, or as the mean $\pm \mathrm{SD}$, as appropriate

b Mantel-Haenszel test (adjusted for age of the elderly requiring care)

c Chi-square test

d Mann-Whitney $U$ test

e The cut-off point was set as the median value

${ }^{\mathrm{f}} t$-test

both medical and rehabilitation services remain unclear since such effects have not always been confirmed in studies performed outside of Japan.
In our study, there was no difference between the successful and unsuccessful groups in the amount of services used or in the proportion of service users. In previous 
Table 7 Comparisons between continuing group and institutionalized group in status of care services use

\begin{tabular}{|c|c|c|c|c|}
\hline Variables $^{\mathrm{a}}$ & $\begin{array}{l}\text { Continuing } \\
\text { group }(n=65)\end{array}$ & $\begin{array}{l}\text { Institutionalized } \\
\text { group }(n=25)\end{array}$ & $p$ value & $\begin{array}{l}\text { Adjusted }^{\mathrm{b}} \\
p \text { value }\end{array}$ \\
\hline Home help service (times/month), mean $\pm \mathrm{SD}$ & $4.7 \pm 7.8$ & $4.7 \pm 8.1$ & $0.735^{\mathrm{c}}$ & $0.882^{\mathrm{e}}$ \\
\hline Home-visit bathing service (times/month), mean \pm SD & $0.3 \pm 1.2$ & $0.0 \pm 0.0$ & $0.207^{\mathrm{c}}$ & $0.319^{\mathrm{e}}$ \\
\hline Home-visit nursing (times/month), mean $\pm \mathrm{SD}$ & $0.4 \pm 2.0$ & $0.0 \pm 0.0$ & $0.207^{\mathrm{c}}$ & $0.319^{\mathrm{e}}$ \\
\hline Home-visit rehabilitation (times/month), mean $\pm \mathrm{SD}$ & $1.2 \pm 2.8$ & $0.7 \pm 2.1$ & $0.394^{\mathrm{c}}$ & $0.882^{\mathrm{e}}$ \\
\hline Day care service (times/month), mean $\pm \mathrm{SD}$ & $4.3 \pm 5.4$ & $7.1 \pm 6.9$ & $0.070^{\mathrm{c}}$ & $0.323^{\mathrm{e}}$ \\
\hline Day rehabilitation service (times/month), mean $\pm \mathrm{SD}$ & $1.9 \pm 4.2$ & $1.9 \pm 4.8$ & $0.845^{\mathrm{c}}$ & $0.751^{\mathrm{e}}$ \\
\hline Short-stay service (times/month), mean $\pm \mathrm{SD}$ & $1.0 \pm 3.2$ & $3.8 \pm 7.2$ & $0.006^{\mathrm{c}}$ & $0.070^{\mathrm{e}}$ \\
\hline Rental of welfare equipment, yes, $n(\%)$ & $38(58.5)$ & $10(40.0)$ & $0.116^{\mathrm{d}}$ & 0.275 \\
\hline Home renovation service, yes, $n(\%)$ & $14(21.5)$ & $0(0.0)$ & $0.009^{\mathrm{d}}$ & 0.050 \\
\hline Quantity of service use (times/month), mean $\pm \mathrm{SD}$ & $11583.7 \pm 8421.6$ & $15323.6 \pm 8299.0$ & $0.050^{\mathrm{c}}$ & $0.761^{\mathrm{e}}$ \\
\hline Degree of service use, mean $\pm \mathrm{SD}$ & $45.3 \pm 27.5$ & $59.0 \pm 28.8$ & $0.049^{\mathrm{c}}$ & $0.943^{\mathrm{e}}$ \\
\hline
\end{tabular}

${ }^{a}$ Data are presented as the number of subjects $(n)$, with the percentage given in parenthesis, or as the mean \pm SD, as appropriate

Degree of service use: quantity of service use/limits to benefits per month, evaluated as (\%)

b Mantel-Haenszel test (adjusted for age of the elderly requiring care)

c Mann-Whitney $U$ test

d The cut-off point was set as the median value

e Chi-square test

studies $[8,10]$, we reported that there was no difference between caregivers who suffered from depressive symptoms and those who did not for the number of various kinds of services. Even though caregivers suffering from depressive symptoms had less money to pay for services, they wanted to utilize such services more [10]. In the present study, it was not clear whether caregivers could use their preferred services. This problem should be clarified in the future.

Factors related to institutionalization

We had expected that caregivers in the institutionalized group would have a heavier burden than those in the in-home care continuing group. However, contrary to our expectation, there was no significant difference in caregivers' burden between the two groups, whose ZBI scores were remarkably higher than the provisional cut-off value of 24-26 [34].

Those findings indicate that not only caregivers in the institutionalized group, but also those engaged in in-home care are under a considerable burden. As shown in Chinese studies [35, 36], in Asian countries, there may be a cultural tendency for family members to feel obliged to shoulder the burden of caregiving without help from others. Because of this tendency, caregivers might suffer from a sense of shame when an elderly family member requires institutionalization. This is in striking contrast to Northern European countries which have highly developed public welfare systems.
Although there was no significant difference in caregivers' burden, more caregivers who suffered from depressive symptoms were observed in the institutionalized group, which is comparable to results of a study conducted before the introduction of LTCIS [37]. It has been reported that caregivers' depressive symptoms are significantly related to the discontinuation of care (e.g. institutionalization or change in caregivers) [38]. Based on our results of this research, we hypothesized that the continuation of inhome care under a cultural burden eventually leads to the caregiver showing symptoms of depression, which makes the continuation of in-home care difficult. Thus, depressive symptoms in caregivers can be regarded as both the results and causes of institutionalization of those requiring care.

In the institutionalized group, daughters-in-law represented a significantly larger percentage of caregivers, which is consistent with the results of another Japanese study [39] conducted before the introduction of the LTCIS. Oura et al. [38] found that elderly males had a lower risk of institutionalization than elderly females, which suggests that the spousal caregivers can continue caring for their husbands at home. Thus, compared to daughters-in-law, spouses (particularly wives) might be more likely to continue in-home care for their partners regardless of the heavy burden. A negative relationship between the person requiring care and his/her daughter-in-law before she takes on the role of caregiver might be one reason for institutionalization.

Compared with their counterparts, a significantly higher proportion of those requiring care in the institutionalized 
group had dementia and more severe behavioural disturbances, which could be explained to a great extent by their older age. Caregivers of the frail elderly with dementia have to watch their charges all day long. When caregivers had time to go out and participate in activities without being accompanied by their charges, the risk of institutionalization was reported to be reduced [38]. As with caregivers' burden, dementia and behavioural disturbances were important factors related to institutionalization. In general, dementia is more common in older people [40, 41]. Due to the fact that there was no significant difference in the duration of in-home care, it is probable that the worsening of dementia due to aging is a factor related to institutionalization, whereas the prolonged period of care is not.

In terms of services, the institutionalized group tended to use short-stay service and tended not to use home renovation service even after adjusting for the age of those requiring care. Caregivers' wishes for rest may result in the popularity of short-stay services in the institutionalized group. The significantly lower rate of home renovation service use in that group suggests that caregivers who have a strong desire to continue in-home care are likely to use home renovation services or that the usage of such services might enable them to continue in-home care.

Our study has several limitations. First, the sampling method of six in-home care management centres among the approximately 2,100 centres in Osaka Prefecture was not random. However, the gender of those requiring care and their caregivers, and the age distribution of those requiring care are similar to those in Japan as a whole [42]. In addition, the participation rate of subjects was $65.5 \%$, which is not considered to be sufficiently high. However, there were no significant differences between the participants and non-participants in terms of age, gender, degree of care and proportion of dementia among those requiring care and caregivers' gender and age (data not shown).

Second, as the determination of dementia was based on a physician's diagnosis rather than a clinical evaluation, the criteria on which dementia was diagnosed is not clear. However, a large-scale cross-sectional study of elderly people requiring care reported that $47.1 \%$ of the elderly had dementia, which is similar to our results [43]. Thus, the dementia diagnoses used in our study can be considered to be valid.

Third, when we investigated factors related to institutionalization, we used only $\mathrm{T} 2$ data for the in-home care continuing group and either T1 or T2 data for the institutionalized group. As the data were collected during different time periods, it is possible that the 'secular trend' had some influence. We should be particularly careful in our interpretation of the duration of caregiving and the ages of the caregivers and the elderly. In other words, it is conceivable that in the continuing group whose data were only from $\mathrm{T} 2$, the duration of caregiving was evaluated to be longer and the ages of those requiring care and caregivers were considered to be older. However, even when we conducted a sub-analysis of the continuing group using only $\mathrm{T} 1$ data, the results did not change (data not shown). Therefore, the findings of this study with respect to factors related to institutionalization can also be considered to be valid.

The aim of Japanese care services is to continue in-home care through centralized and efficient medical, welfare and health services. The results of our study suggest that consulting a physician and rehabilitation for dementia and behavioural disturbances in short-stay and day care services might reduce caregivers' burden and enable them to continue in-home care. The use of home renovation services might also be effective for continuing in-home care.

Acknowledgements We express our sincere appreciation to the staff members of in-home care management centres for their excellent data collection.

Conflict of interest None.

\section{References}

1. Zarit SH, Reever KE, Bach-Peterson J. Relatives of impaired elderly: correlates of feelings of burden. Gerontologist. 1980;20: 649-55.

2. Schulz R, Williamson GM. A 2-year longitudinal study of depression among Alzheimer's caregivers. Psychol Aging. 1991;6:569-78.

3. Schulz R, McGinnis KA, Zhang S, Martire LM, Hebert RS, Beach SR, et al. Dementia patient suffering and caregiver depression. Alzheimer Dis Assoc Disord. 2008;22:170-6.

4. Eklund K, Wilhelmson K. Outcomes of coordinated and integrated interventions targeting frail elderly people: a systematic review of randomised controlled trials. Health Soc Community. 2009; $17: 447-58$.

5. Gaugler JE, Kane RL, Kane RA, Clay T, Newcomer R. Caregiving and institutionalization of cognitively impaired older people: utilizing dynamic predictors of change. Gerontologist. 2003;43:219-29.

6. Ministry of Health, Labour and Welfare. Creating a society where elderly can be active and comfortable. In: Annual Health, Labour and Welfare Reports on 2005-2006 (in Japanese). Tokyo: Gyosei; 2006. p. 252-64.

7. Arai Y, Washio M. Burden felt by family caring for the elderly members needing care in southern Japan. Aging Ment Health. 1999;3:158-64.

8. Washio M, Wada J, Tokunaga S, Arai Y, Mori M. Long-term care insurance for elderly and depression among caregivers of the frail elderly in urban Japan: a follow-up study. Int Med J. 2002;9:251-5.

9. Washio M, Arai Y, Izumi H, Mori M. Burden on family caregivers of frail elderly persons one year after the introduction of public long-term care insurance service in the Onga District, 
Fukuoka Prefecture: evaluation with a Japanese version of the Zarit caregiver burden interview (in Japanese). Nippon Ronen Igakkai Zasshi. 2003;40:147-55.

10. Washio M, Oura A, Arai Y, Mori M. Depression among caregivers of the frail elderly: three years after the introduction of public long-term care insurance for the elderly. Int Med J. 2003;10:179-83.

11. Tanji H, Ootsuki M, Matsui T, Maruyama M, Nemoto M, Tomita $\mathrm{N}$, et al. Dementia caregivers' burdens and use of public services. Geriatr Gerontol Int. 2005;5:94-8.

12. Oura A, Washio M, Arai Y, Ide S, Yamasaki R, Wada J, et al. Depression among caregivers of the frail elderly in Japan before and after the introduction of the Public Long-Term Care Insurance System. Z Gerontol Geriatr. 2007;40:112-8.

13. Washio M, Saitoh S, Arai Y, Takagi S, Oonishi H, Isobe T, et al. Risk factors for heavy burden among family caregivers in a rural town in Hokkaido (in Japanese). Nippon Ronen Igakkai Zasshi. 2005;42:221-8

14. Arai Y, Zarit SH, Sugiura M, Washio M. Patterns of outcome of caregiving for the impaired elderly: a longitudinal study in rural Japan. Aging Ment Health. 2002;6:39-46.

15. Okamoto K, Hasebe Y, Harasawa Y. Caregiver psychological characteristics predict discontinuation of care for disabled elderly at home. Int J Geriatr Psychiatry. 2007;22:1110-4.

16. Arai Y, Kudo K, Hosokawa T, Washio M, Miura H, Hisamichi S. Reliability and validity of the Japanese version of the Zarit Caregiver Burden interview. Psychiatry Clin Neurosci. 1997;51: 281-7.

17. Arai Y. Application of the Japanese version of the Zarit Caregiver Burden interview (in Japanese). Igaku No Ayumi. 1997;186: 930-1.

18. Shima S, Shikano T, Kitamura T, Asai M. Reliability and validity of CES-D (in Japanese). Clin Psychiatry. 1985;27(6):717-23.

19. Matsumoto N, Ikeda M, Fukuhara R, Hyodo T, Ishikawa T, Mori $\mathrm{T}$, et al. Validity and reliability of the Japanese version of the Neuropsychiatric Inventory Caregiver Distress Scale (NPI-D) and the Neuropsychiatric Inventory Brief Questionnaire Form (NPI-Q). Brain Nerve. 2006;58:785-90.

20. Radloff L. The CES-D scale: a self-report depression scale for research in the general population. Appl Psychol Meas. 1977;1: 385-401.

21. Kaufer DI, Cummings JL, Ketchel P, Smith V, MacMillan A, Shelley T, et al. Validation of the NPI-Q, a brief clinical form of the Neuropsychiatric Inventory. J Neuropsychiatry Clin Neurosci. 2000;12:233-9.

22. Arai Y, Kumamoto K, Washio M, Ueda T, Miura H, Kudo K. Factors related to feelings of burden among caregivers looking after impaired elderly in Japan under the long-term care insurance system. Psychiatry Clin Neurosci. 2004;58:396-402.

23. Yaffe K, Fox P, Newcomer R, Sands L, Lindquist K, Dane K, et al. Patient and caregiver characteristics and nursing home placement in patients with dementia. Am Med Assoc. 2002;287:2090-7.

24. Whitlatch CJ, Zarit SH, Eye AV. Efficacy of interventions with caregivers: a reanalysis. Gerontologist. 1991;31:9-14.

25. Matsuu K, Washio M, Arai Y, Ide S. Depression among caregivers of the frail elderly in urban Japan. Psychiatry Clin Neurosci. 2000;54:553-7.

26. Kuwahara Y, Washio M, Arai Y. Burden among caregivers of frail elderly in Japan. Fukuoka Igaku Zasshi. 2001;92:326-33.
27. Washio M, Arai Y. Depression among caregivers of the disabled elderly in southern Japan. Psychiatry Clin Neurosci. 1999;53:407-12.

28. Pinquart M, Sörensen S. Associations of stressors and uplifts of caregiving with caregiver burden and depressive mood: a metaanalysis. J Gerontol Psychol Sci. 2003;58:112-28.

29. Kumamoto K, Arai Y, Zarit SH. Use of home care services effectively reduces feelings of burden among family caregivers of disabled elderly in Japan: preliminary results. Int J Geriatr Psychiatry. 2006;21:163-70.

30. Ulstein I, Wyller TB, Engedal K. Correlates of intrusion and avoidance as stress response symptoms in family carers of patients suffering from dementia. Int $\mathrm{J}$ Geriatr Psychiatry. 2008;23:1051-7.

31. Machnicki G, Allegri RF, Dillon C, Serrano CM, Taragano FE. Cognitive, functional and behavioral factors associated with the burden of caring for geriatric patients with cognitive impairment or depression: evidence from a South American Sample. Int J Geriatr Psychiatry. 2009;24:382-9.

32. Mossello E, Caleri V, Razzi E, Bari MD, Cantini C, Tonon E, et al. Day care for older dementia patients: favorable effects on behavioral and psychological symptoms and caregiver stress. Int J Geriatr Psychiatry. 2008;23:1066-72.

33. Graff MJL, Vernooij-Dassen MJ, Thijssen M, Dekker J, Hoefnagels WHL, OldeRikkert MGM. Community based occupational therapy for patients with dementia and their care givers: randomised controlled trial. Br Med J. 2009;333:1196-9.

34. Schreiner AS, Morimoto T, Arai Y, Zarit S. Assessing family caregiver's mental health using a statistically derived cut-off score for the Zarit Burden Interview. Aging Ment Health. 2002;10:107-11.

35. Ho SC, Chan A, Woo J, Chong P, Sham A. Impact of caregiving on health and quality of life: a comparative population-based study of caregivers for elderly persons and noncaregivers. J Gerontol Ser A Biol Sci Med Sci. 2009;64:873-9.

36. Zhan HJ. Joy and sorrow: explaining Chinese caregivers' reward and stress. J Aging Stud. 2006;20:27-38.

37. Arai Y, Sugiura M, Washio M, Miura H, Kudo K. Caregiver depression predicts early discontinuation of care for disabled elderly at home. Psychiatry Clin Neurosci. 2001;55:379-82.

38. Oura A, Washio M, Wada J, Arai Y, Mori M. Factors related to institutionalization among the frail elderly with home-visiting nursing service in Japan. Gerontology. 2006;52:66-8.

39. Arai Y, Washio M, Kudo K. Factors associated with admission to a geriatric hospital in semisuburban southern Japan. Psychiatry Clin Neurosci. 2000;54:213-6.

40. Jagger C, Lindesay J. Residential care for elderly people: the prevalence of cognitive impairment and behavioural problems. Age Ageing. 1997;26:475-80.

41. Hirakawa Y, Kuzuya M, Enoki H, Hasegawa J, Iguch A. Caregiver burden among Japanese informal caregivers of cognitively impaired elderly in community settings. Arch Gerontol Geriatr. 2008;46:367-74.

42. Ministry of Health, Labour and Welfare. Comprehensive Survey of Living Conditions of the People on Health and Welfare 2007 (in Japanese). Available at: http://www.mhlw.go.jp/toukei/list/ 20-19-1.html. Accessed 9 Sep 2008.

43. Endo T, Ebina N, Mochizuki M, Onodera A, Nagashima K. Investigating family caregivers' burden and subjective quality of life among elderly of requiring support and requiring care (in Japanese). J Health Welf Stat. 2009;15:34-41. 